Article

\title{
Why Context Matters: Social Inclusion and Multilingualism in an Austrian School Setting
}

\author{
Ulrike Jessner ${ }^{1,2, *}$ and Kerstin Mayr-Keiler ${ }^{3}$ \\ ${ }^{1}$ Department of English, University of Innsbruck, 6020 Innsbruck, Austria; E-Mail: ulrike.jessner@uibk.ac.at \\ 2 Doctoral School of Multilingualism, Institute of Hungarian and Applied Linguistics, University of Pannonia, 8200 Veszprém, \\ Hungary \\ ${ }^{3}$ Centre for Research and Knowledge Management, Pedagogical University Tyrol, 6020 Innsbruck, Austria; \\ E-Mail: kerstin.mayr-keiler@ph-tirol.ac.at \\ * Corresponding author
}

Submitted: 18 August 2017 | Accepted: 10 November 2017 | Published: 22 December 2017

\begin{abstract}
This article draws attention to language choice and language use of Austrian bi- and multilingual school children. We explore some implications of their linguistic practices with regard to social inclusion in an Austrian educational school setting. Pursuing a Dynamic Systems and Complexity Theory approach, we hypothesise that before language users actually use a language within a certain context, they have to evaluate the respective communicative situation by taking multiple contextual factors into consideration, meaning language users choose to use, or not to use, a language based on the socio-contextual information at hand. We consider these contextual factors to be most relevant as they provide the basis on which speakers can actually make use of a certain language within a given context. By drawing on examples of empirical data obtained through a language background survey, we examine some of the complex and dynamic interactions of contextual parameters influencing language choice and language use in the formal educational setting of classroom instruction. Based on the results of this study, we display a selection of the dynamic and complex interactions of pupils' language use in one specific context as well as their language preferences and how these relate to social inclusion.
\end{abstract}

\section{Keywords}

complexity; context; education; language use; multilingualism; social inclusion; sociolinguistics

Issue

This article is part of the issue "Multilingualism and Social Inclusion", edited by László Marácz (University of Amsterdam, The Netherlands/Gumilyov Eurasian National University, Kazakhstan) and Silvia Adamo (University of Copenhagen, Denmark).

(C) 2017 by the authors; licensee Cogitatio (Lisbon, Portugal). This article is licensed under a Creative Commons Attribution 4.0 International License (CC BY).

\section{Introduction}

Over the last few decades Austria, like other European countries, has developed into a culturally and linguistically diverse country due to growing mobility and migration, as well as increasing globalisation. Thus, the Council of Europe (2014) eagerly promotes cultural and linguistic diversity through carrying out great numbers of initiatives and programmes to support EU member states' policy development for establishing a:
Democratic, socially inclusive, cohesive, healthy and just society with respect for fundamental rights and cultural diversity that creates equal opportunities and combats discrimination in all its forms. (Commission of the European Communities, 2005, p. 4)

Although the EU proclaims social inclusion and full respect for cultural and linguistic diversity (Franke \& Mannella, 2017, p. 1; cf. also European Commission, 2000, p. 13), critical voices among scholars are raised concerning a gap between political intentions and enactments, 
and their actual execution. Gal (2006) relating to Anderson (1983) shows her concern on this critical issue:

Yet, this emphasis on linguistic diversity is deceptive. To be sure, there is recognition of national language, minority and regional language, foreign, migrant and third-country languages; mother tongues, sign languages, lesser used languages, ethnic minority, indigenous and non-territorial languages. Nevertheless, all the linguistic practices considered worthy of mention conform to standardising and Herderian assumptions: they are named languages with unified, codified norms of correctness embodied in literatures and grammars. No other configurations of speaking are recognised. (p. 167)

Accordingly, linguistic knowledge and competence on national state levels and especially in educational contexts still seem to be measured against concepts of standardised language norms. In Austria competence in the standardised German variety therefore seems to be representative for language competence in general and is still considered an indicator for social inclusion. Thus, language competence almost invariably refers to the competence in the majority or national language of the host country. In the Austrian report on Migration \& Integration 2016 the level of language knowledge of German and the level of education are identified as two out of five core indicators (Statistik Austria, 2016, p. 15) for integration (based of the National Action Plan), whereas other linguistic skills of bi- and multilingual language users are not taken into account. As Krumm (2003, p. 413f) points out, integration in Austria seems frequently understood as the command of the German language or, in other words, linguistic assimilation. Accordingly, the Federal Ministry for Education in Austria issued a regulation on language education in June 2017 which requires schools in Austria to identify and promote the oral competence of all pupils in the German language and argues that:

[T] he acquisition or the knowledge of the German language of instruction and education is the basis for participation in all educational processes and is therefore an essential prerequisite for school success and subsequent integration into the labour market as well as for participation in political, economic, cultural and social life Austria. (2017, p. 1, translated by the authors)

German is here clearly presented as the target language upon which educational, political, economic, cultural, and social participation is based. Consequently, educational language programmes, particularly those which strongly emphasise the teaching and learning of German only (e.g., courses like German as second or foreign language), are promoted by the Federal Ministry for Education. However, such programmes and courses, as well as language instruction in Austrian schools in general, do not usually pay enough attention to findings of cur- rent research on multilingualism with regard to language learning. Research on language learning in the context of multilingualism shows that making use of already existing linguistic resources supports and benefits further language learning processes (e.g., Herdina \& Jessner, 2002; Hufeisen \& Marx, 2014). Nevertheless, pupils' linguistic resources, their knowledge of languages and language varieties, as well as their knowledge about language systems other than the German standard variety, are insufficiently considered as relevant existing knowledge on which to build when teaching and learning a second, third etc. language (in this case German). Consequently, language learning instruction in Austrian schools, as well as special German-teaching programmes in Austria, predominantly follow a tradition which is based on notions such as one-language-one-nation, the standardised variety of German as well as an idealised native speaker. Apart from that, little or no consideration has been given to contextual framework conditions that provide opportunities for pupils to make use of their full linguistic repertoires and resources.

Focusing on the latter aspect, this article aims at a better understanding of the complexity of contextual factors which provide pupils with opportunities to actually make full use of their language resources in education contexts. To do this, we will have to identify contextual factors that must be considered individually as well as in their interplay. We therefore address the question of which factors influence multilingual pupils to choose, activate, and actually use certain languages in educational contexts. We hypothesise that contextual factors such as situational setting, interlocutors, and communicative needs are among the main driving forces for language choice and language use. By taking these factors into account, we wish to contribute to a deeper understanding of probable reasons for prioritizing certain languages over others in educational contexts, thus affecting linguistic and, consequently, social participation at school.

In the following, we will first outline some relevant educational-political considerations regarding the Austrian context. Secondly, we will provide the conceptual and methodological frames and thus, the lenses through which contextual factors are approached with regard to language choice and language use at school. To make sense of the complex multicultural and multilingual encounters in the context of diversity, we consider the framework of Dynamic Systems and Complexity Theory (henceforth DSCT) most appropriate. In the study, we present findings from a language background survey of bi- and multilingual school children attending New Middle School (comparable to secondary modern school) in Innsbruck (Tyrol/Austria). The aim of the current study is to investigate the interrelations between contextual factors and language choice and use of bi- and multilingual pupils in an Austrian school context, and relate them to issues regarding teaching methods and social inclusion. 


\section{Multilingualism in the Austrian Educational Context}

\subsection{Austrian Language Policy and Status Quo}

According to the Language Educational Policy Profile: Country Report Austria (2008):

Austria has successfully developed a language policy for schools and in general education that is geared to supporting plurilingualism, as well as effective structures for the planning and discussion of language policy issues: in concert with decisions and programmes of the Council of Europe and of the European Union, these undergo consistent further development. By way of contrast, the linguistic wealth of migrants, and that of minority and neighbouring languages, is hardly made use of in educational practice. (Federal Ministry for Education, Arts and Culture \& Federal Ministry for Science and Research Austria, 2008, p. 28)

As it becomes obvious in the Language Educational Policy Profile (2008), Austria's worthy endeavours in promoting multilingualism have not yet become effective in educational teaching and learning practices. Although linguistic diversity and intercultural dialogue have been promoted, Austria's focus is still on reinforcing the acquisition of the standardised German variety as the single official, national state language (Federal Constitutional Law, 1930/2005). Despite official governmental acknowledgement of minority languages (e.g., Hungarian, Czech, Slovenian, etc.), the government stands by its position that German is and has to be the only target language through which social inclusion is to be legitimized. According to the Austrian National Education Report 2015 "weaknesses in the language of instruction [German] are a risk to school success" (Bruneforth, Lassnigg, Vogtenhuber, Schreiner, \& Breit, 2016, p. 28, translated by the authors).

Thus, broadly speaking, migration and little command of German are still indicators for social and educational inequality and high risk in Austria. As stated in the recently published Austrian National Education Report 2015, more and more children predominantly using everyday languages other than German are classified as pupils with special educational needs (SPF). The SPF-ratio of $7.1 \%$ for young people at grades five through eight who use other languages than German on a daily basis is considerably higher than for German-speaking pupils whose ratio is $4.1 \%$. Children with non-German heritage languages thus have a $54 \%$ higher risk of receiving an SPF (Bruneforth et al., 2016, p. 98). ${ }^{1}$ At the same time, these children attend classes with high proportions of fellowpupils with non-German everyday languages, which is considered a strong factor of educational segregation:

Since the change in the school and class composition is only limited by the influence of school policy action, the question arises as to which measures are necessary to improve the quality of teaching in this segregated education. (Bruneforth et al., 2016, p. 44)

\subsection{The Role of Teachers and Schools in Austria}

Presently, teachers in Austria face the challenge of managing language learning during classroom instruction in a tailored way, e.g., conducting standardised language tests normed on monolingual German native speakers. These tests are first and foremost designed and executed to evaluate the pupils' level of proficiency in the German standard variety. Although there have been international efforts to develop tests that are valid for several languages and/or to take metalinguistic competences into account (e.g., Jessner, Hofer, \& Pinto, 2015), critical research on language testing (e.g., Shohamy, 2001) shows that tests are still mainly developed against the background of western cultural concepts of socialisation (Lengyel, 2012, p. 17). Most tests may thus still be seen as instruments of educational and socio-political power, both neglecting and excluding any other of the pupils' linguistic resources than the standard target language variety. Accordingly, the notion of one-language-one-nation still seems to be resonating and thus indicating that traditional European language ideologies are (sought to be) preserved (e.g., Weber \& Horner, 2012, p. 18f). The difficulties that arise are that results of those legally binding language tests in Austria build an important basis for teachers' educational practices. At the same time, teachers in Austria are obliged to follow the curriculum and thus have to incorporate all of their pupils' linguistic resources in class (Federal Ministry for Education, 2012, p. 8). If, however, the pupils' competence in the standardised German variety is considered to be most crucial for educational success in the Austrian school system, as well as for social inclusion, teachers may give top priority to teaching the standardised German variety. Due to lack of appropriate alternative testing instruments, little didactical and methodological knowledge on how to include (all) their pupils' linguistic resources in class, andlast but not least-lack of time, opportunities for pupils to make use of their linguistic resources other than German has been reduced to a minimum.

Thus, teachers in Austria are faced with contradictory and thus challenging contexts and interests. Teachers and schools are obliged to follow and act out national state and governmental interests (and power) which are still based on latent ideas of homogeneity (uniformity) such as homogeneity of languages, homogeneity of cultures, and homogeneity of populations, which are at the source of state ideologies of language and identity. Consequently, children equipped with diverse sets of linguistic resources cannot yet equally make use of their language knowledge and competences within educational settings since they still find themselves embedded in monolingually and monoculturally biased school

\footnotetext{
${ }^{1}$ Gomolla and Radtke (2009) present similar results for Germany with regard to the proportion of migrant children in special schools.
} 
contexts (e.g., Gogolin, 2008). However, schools need to be:

[U]nderstood both as sites of production and distributions of all kinds of resources, including linguistic ones, and as sites of discursive construction of ideologies of language, identity and nation, and of social categories. (Heller, 2012, p. 27)

Thus, in order to learn more about the consequences derived from this difficult positioning of teachers and schools in Austria, we need to look more closely at the complex composition of educational contexts and what implications they have for pupils' linguistic and thus social participation.

\section{Conceptual and Methodological Frames}

\subsection{Dynamic Systems and Complexity Theory (DSCT)}

Making use of linguistic resources in various contexts depends as much on the individual's linguistic competence, his/her language knowledge and his/her willingness or desire (Kristeva, 1980) to use a specific language as it does on the specific socio-cultural and socio-political contexts, which can either elicit, restrict or, at worst, even prohibit the activation and making use of language resources and thus-at least to some extent-inhibit social participation.

Trying to follow these complex, and multi-layered structures of language choice and language use, we depend on scientific approaches best suited to address the complexity of interactions of a multitude of factors at different levels. Such an approach is offered by the DSCT and its application to second language acquisition (e.g., De Bot, Lowie, \& Verspoor, 2007; Dörnyei, Maclntyre, \& Henry, 2014; Larsen-Freeman \& Cameron, 2008) and multilingualism (Herdina \& Jessner, 2002). Instead of perceiving entities, actions, and their interactions as isolated, bound, static and linear, DSCT tells us to shift our focus of attention to the transmutational and emerging quality of interconnections between entities and (inter)actions. Thus, DSCT forms an appropriate framework for our discussion of the interconnections between contextual factors involved in language choice and use in a formal education setting.

However, apart from the large frame of DSCT, we need some kind of prism or lens that allows for analytical and critical inquiry of the actual practice of language use within the realms of educational contexts in which pupils enact their choice of specific linguistic resources. Such a lens is offered by one of the conceptual and methodological frames of interactional sociolinguistics which examines socio-cultural, socio-political, and ideological conditions under which languages are used in certain contexts (e.g., Irvine \& Gal, 2000; Silverstein, 1979; Woolard \& Schieffelin, 1994) and thus complements the DSCT approach.

\subsection{Concepts of Context}

The concept of context is of constitutive importance when it comes to investigating the complex dynamics of language choice and use. Researchers in the field of poststructural interactional, educational and cognitive (socio)linguistics promote and argue for a DSCT understanding of context(s) through which language evolves. Pursuing a DSCT and interactional sociolinguistic approach (e.g., van Dijk, 2010), we hypothesise that before language users actually use a language within a certain context, they have to evaluate the respective communicative setting by taking multiple parameters (that constitute a specific communicative situation) into considerationi.e., language users make their choice to use or not to use a particular language based on the socio-contextual information at hand. Their ability to recognize, interpret, and make (communicative) use of this information is influenced by a variety of contextual factors - all of which constituting a language user's multi-competence, which Cook describes as "the overall system of a mind or a community that uses more than one language" (2012; Cook \& Li Wei, 2016, p. 3). Moreover, the choices language users make index their subject positions. Davies and Harré define a subject position in the following way:

A subject position incorporates both a conceptual repertoire and a location for persons within the structure of rights for those that use that repertoire. Once having taken up a particular position as one's own, a person inevitably sees the world from the vantage point of that position and in terms of the particular images, metaphors, storylines and concepts which are made relevant within the particular discursive practice in which they are positioned. At least a possibility of notional choice is inevitably involved because there are many and contradictory discursive practices that each person could engage in. (Davies \& Harré, 1990, p. 46)

Accordingly, language users position themselves by deciding to use or not to use a particular language (variety, register, etc.) within a particular context (e.g., Kramsch, 2015, p. 20; Pennycook, 1994, p. 128). Interactional contexts, therefore, are not to be considered as simply consisting of given social structures pre-defined by objective parameters but rather as dynamic systems that are constantly (re-)created through the interactions between language users, the intersection of contextual parameters (e.g., culture, social class, social role, social setting, political discourse), the users' communicative goals, communicative needs and-in particular-the emerging structures resulting from these interactions.

However, since a direct link between contextual structures and how people speak (or which language they use) cannot be observed, we can only relate language use to contexts through the mind of language users (e.g., Kecskes, 2008, pp. 385ff). This perspective is 
in accordance with DSCT, which considers the mind as an open system, where there is no separation between mind and environment, and was outlined, for example, by Larsen-Freeman and Cameron (2008): "An open system cannot be independent of its context since there is a flow of energy or matter between system and environment; the context is part of the system and its complexity" (p. 34). Thus, the concept of context can be seen as a relational one consisting of:

[F]ive dimensions: linguistic, situational, interactional, as well as the cultural and intertextual. It is shaped by people in dialogue with one another in a variety of roles and statuses. Because language is at the intersection of the individual and the social of text and discourse, it both reflects and construes the social reality called "context". (Kramsch, 1993, p. 67)

In this article we focus on the first three dimensions, which are linguistic, situational, and interactional, in an educational setting and try to find out more about the complex interrelations between these dimensions creating contexts and thus influencing pupils' language choice and use. Contexts, however, are not to be perceived as static and fixed. When it comes to language teaching and learning in inclusive settings in particular, it seems of utmost importance to arrive at a well-informed understanding of how even the slightest shifts, changes, and differences in weighting of factors constituting these dimensions may create totally different conditions for choosing to use or not to use a particular language or draw on a particular linguistic resource (register, variety, etc.). From a DSCT approach, contexts can thus be regarded as emergent systems which are by definition neither fixed nor precisely predictable, since they are constantly (re-)constructed. Accordingly, Herdina and Jessner (2002) present the perceived communicative needs of the multilingual individual as a crucial element of language development, meaning that learning and using a language or languages are defined and formed by the societal framework in which communication and learning take place.

By trying to take these aspects into account, we attempt to raise awareness for the dynamic interplay between contextual factors in order to arrive at a dynamic understanding of language choice and language use in linguistically diverse educational contexts. We thereby hope to contribute to a more inclusive understanding of contextual factors providing pupils with opportunities to draw on specific linguistic resources.

\section{The Austrian Study}

The present study aims at investigating the complexity of pupils' making use of their reported linguistic repertoires in a formal educational context. It forms part of a largescale study carried out by Mayr-Keiler (forthcoming). This article will specifically answer the following questions:
(1) Can bi- and multilingual pupils make use of languages other than German in a formal educational context? If so, which languages can they make use of?

(2) Which contextual factors affect the actual making use of languages other than German for bi- and multilingual children in a formal educational setting?

Within the context of this article 'formal context' is defined as the official, educational school context, in which pupils use language during lessons to interact with their teachers in order to participate in class on or off-task.

\subsection{Methodology}

\subsubsection{Subjects}

The subjects of the large-scale study are 437 pupils attending three New Middle Schools in the urban area of Innsbruck, Tyrol, Austria. All three schools are located in school districts with a high proportion of migrants and thus are culturally and linguistically diverse.

\subsubsection{The Language Background Questionnaire}

Data for the study were collected through a pencil and paper questionnaire based on the language background scale of Baker (1992) and Extra and Yagmur (2004). The questionnaire was designed to collect data on the language choices and the oral language use of mono-, bilingual and multilingual pupils attending a New Middle School between the ages of ten and fifteen years. Since the test was conducted in German, we considered question formats pupils are most likely to be acquainted with. The first section of the survey collected background information concerning age, gender, school attendance, school grade, and language history. In the second section participants were asked about their language choices and use in detail and it contains, among others, questions on the following aspects:

- Individual linguistic repertoires (e.g., With how many languages and with which languages did you grow up?);

- Oral language use in the three different contexts.

Since this article focuses on language choice and use in a formal educational setting, we present only the questions dealing with formal context (Which languages are you taught at school and for how long?; Which languages do you use with your class teacher during classroom instruction (additional ranking of languages was asked); Which languages do you use with your classmates during lessons?; Which languages do you use for chatting during lessons?)

- Language attitudes (What are your favourite languages and why/why not?). 
Furthermore, subjects were asked to provide information concerning the languages they use for specific topics with their friends, the languages they use on the phone (and with whom), for listening to music and watching TV. Other questions concerned the pupils' favourite and nonfavourite languages. All sections provided the possibility for multiple answers with closed questions as well as the possibility for additions provided by the pupils in open questions. Moreover, subjects were asked to rank their answers according to priority.

\subsubsection{Data Analysis and Methods}

The present study relies on results gained through univariate and bivariate analyses of the input variables mono-, bi- and multilingualism, German, English or other languages reported by the participants as L1, L2, L3 and $\mathrm{Ln}$ as well as the oral use of these languages in the formal educational context. This analysis was performed using the computing environment $\mathrm{R}$ ( $\mathrm{R}$ Development Core Team, 2005). In addition, we performed an intersection analysis of the following contextual variables included in the data:

- Provision of optional language courses at the schools investigated;

- Pupils participation in optional language courses provided at school;

- Duration of attendance in optional language courses (time of exposure).

We thus created intersecting sets to show which of the reported languages included in the pupils' linguistic repertoire are actually used in a formal educational setting and to show how these contextual variables influence the pupils' opportunity to actually make use of languages other than German. In this study, we will only refer to results concerning the language use of biand multilinguals.

\section{Results}

\subsection{General Findings}

Of the 437 subjects who participated in the study $39.36 \%$ reported to be bilingual $(N=172)$ and $10.07 \%$ stated to be multilingual $(N=44)$. Bilingual pupils reported the following languages as their L1: Turkish ( $N=55)$, BosnianSerbian-Croatian (BKS) $(\mathrm{N}=40)$, Iranian languages (a variety of Kurdish or Persian) ( $N=3)$, Arabic $(N=5)$, Romance languages (Italian or Rumanian) $(N=10)$, other languages $(N=11)$. 48 of the bilinguals mentioned German as their L1. As for the multilingual pupils $(N=44)$, $59.1 \%$ stated to have an L1 other than German ( $N=26)$. Among the multilingual pupils' $(\mathrm{N}=44)$ reported L1 we find the following languages: Turkish $(N=6)$, a Romance language (Italian, Portuguese, French, Spanish or Romanian) $(\mathrm{N}=6)$, an Iranian language (a variety of Kurdish or Persian) $(N=5)$, other languages $(N=4)$, Arabic, a variety of German dialect and English were each mentioned once.

However, taking all the languages reported by bi- and multilinguals either as L1, L2, L3 and L3+ into account, we can define a set of languages (henceforth referred to "reported linguistic repertoire") and see the following languages included in the bi- and multilinguals reported linguistic repertoire based on the number of responses ( $N=481$ ) (see Figure 1).

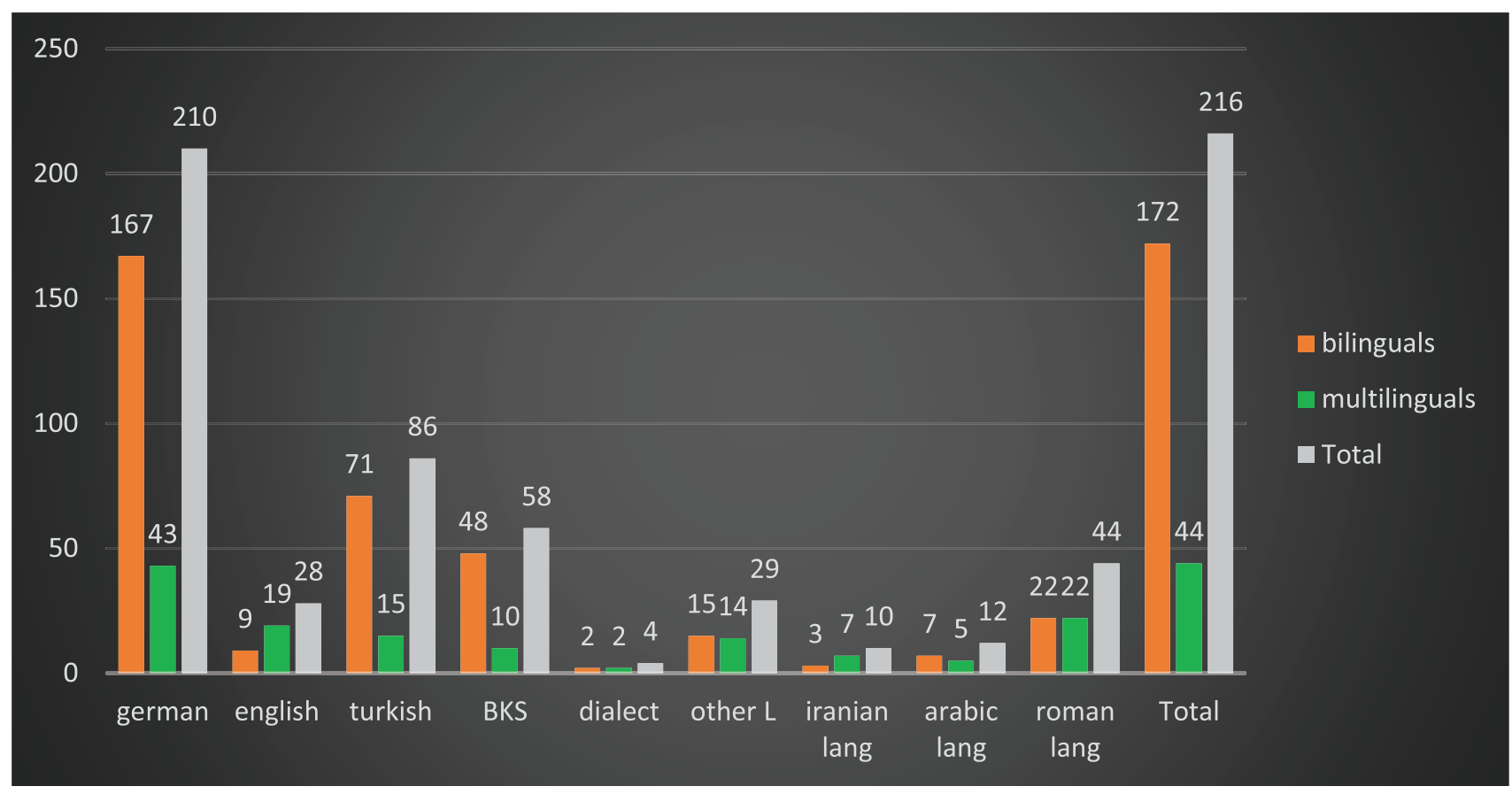

Figure 1. Languages included in bi- $(N=172)$ and multilinguals' $(N=44)$ reported linguistic repertoire. 
As shown in Figure 1, 210 out of 216 bi- and multilinguals have German in their reported linguistic repertoire. Turkish, BKS and Romance languages have the greatest share in the bi- and multilinguals' reported linguistic repertoires. Findings, however, (cf. Section 5.2 in this article) will show that most of the languages included in the bi- and multilingual pupils' linguistic repertoire are rarely or not used at all as a resource for interacting with their class teachers during classroom instruction. The only languages used (except for German) are English or a Romance language. Therefore, we focus on these two languages in the following.

\subsection{The Use of Italian and English in a Formal Educational Context}

Since German is the language of instruction and education in Austria (see introduction) results correspondingly show that $98,6 \%$ of the bi- and multilingual $(N=216)$ pupils use German as a first language with their teacher during classroom instruction. As outlined before in Section 2.2 in this article, however, social (including linguistic and cultural) inclusion means to provide pupils with opportunities which allow them to make use of their (linguistic) resources other than German to support their learning, so attention is also drawn to if and how bi- and multilingual pupils can make use of these linguistic resources in a formal educational context.

Results show that about $60 \%$ (129 out of 216) of the bi- and multilingual pupils actually make use of an additional language other than German, namely Italian and English, during classroom instruction. Both of them are first or second foreign languages which are obligatorily offered at schools in Austria. English and Italian can therefore be considered as socially "unmarked" languages within a formal educational context. Most of the other languages included in the reported linguistic repertoires of bi- and multilingual pupils are rarely or not used at all as a resource for interacting with their class teachers during classroom instruction.

\subsubsection{Bilingual Pupils}

$55.8 \%$ of the bilinguals ( $N=96$ ) reported to use an additional language with their class teachers. 81 pupils reported to use English as a second language with their class teachers (see Figure 2). However, only 9 of them reported to have English included in their linguistic repertoire (see Figure 1). This means, we can find a discrepancy between the existence of English in their repertoire and their actual use of English as a second language in the formal educational context with their class teacher.

Among those bilinguals who listed a Romance language (Romanian, $\mathrm{N}=10$; French, $\mathrm{N}=1$, Spanish, $\mathrm{N}=1$; Italian, $\mathrm{N}=10$ ) in their linguistic repertoire ( $\mathrm{N}=22$; cf. Figure 1) only 5 of those who mentioned Italian ( $N=10)$ actually use Italian with their class teacher (cf. Figure 2). In contrast to the bilinguals' use of English, Italian is only used by those bilinguals who have Italian included in their linguistic repertoire.

\subsubsection{Multilingual Pupils}

$75 \%$ of the multilinguals ( $N=33$ out of $N$ total $=44$ ) reported to use an additional language with their class teachers. 24 out of 44 multilinguals reported to use English as a second or a third language with their class teacher. However, 19 of them reported to also have English included in their linguistic repertoire. In contrast to the bilinguals, there seems to be a greater concordance between reporting English included in the linguistic repertoire and making use of English in the formal educational context.

22 multilingual pupils mentioned having a Romance language in their repertoire (cf. Figure 1) whereby 13 mentioned Italian and 9 pupils either mentioned Rumanian $(N=3)$ or Spanish, French, or Portuguese $(N=6)$. Again, those 13 multilinguals that mentioned making use of Italian during classroom instruction (see Figures 3 and 4), are those who have Italian included in their linguistic repertoire. Multilinguals listing other Romance languages mentioned not making use of these languages in the formal educational context.

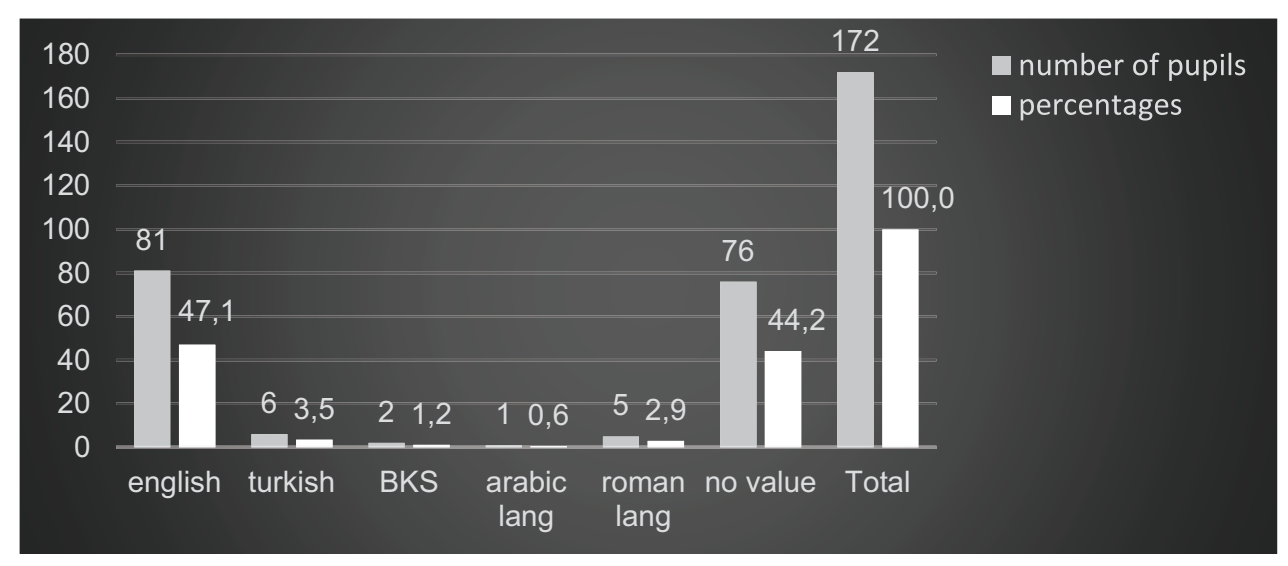

Figure 2. Bilingual pupils' reported languages used as a second language with class teacher. 


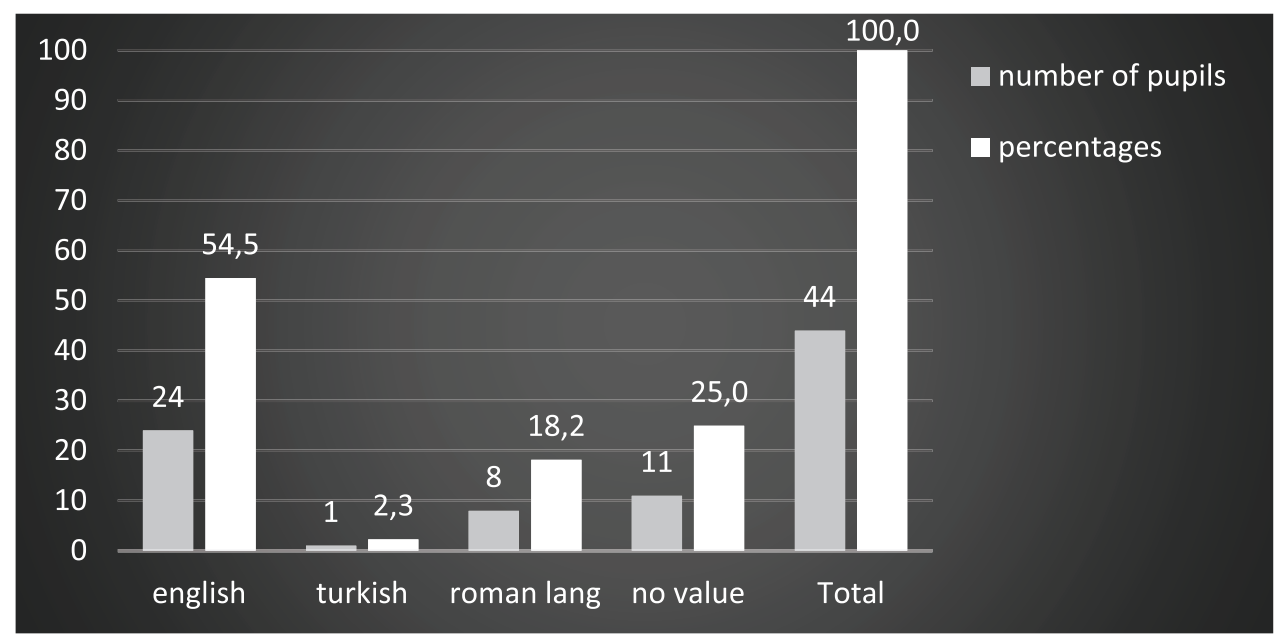

Figure 3. Multilingual pupils' reported languages used as a second language with class teacher.

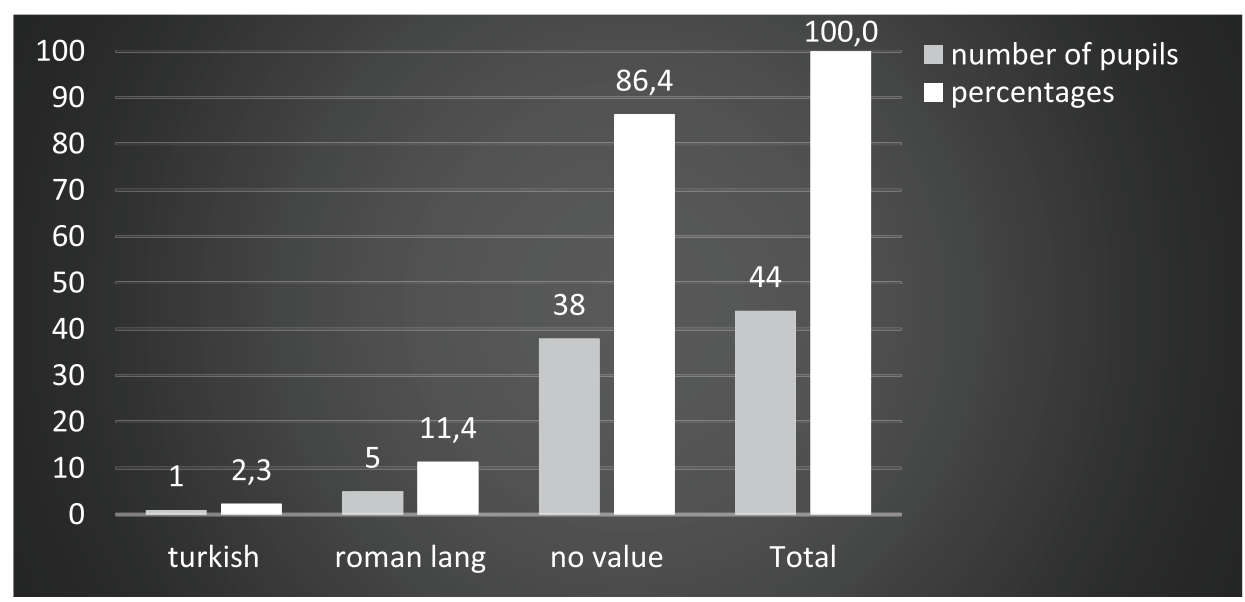

Figure 4. Multilingual pupils' reported languages used as a third language with class teacher.

In summary, we find a discrepancy concerning the actual use of English in the formal educational context and its inclusion in the pupils' linguistic repertoire. While for the bilinguals there seems to be no direct relation between 'English included in their linguistic repertoire' and their making use of it for interacting with their class teacher, multilinguals show to have a greater concordance between these factors. Concerning the use of Italian, however, only those bi- and multilinguals that have Italian included in their linguistic repertoire actually make use of Italian in the formal educational context. Moreover, both bi- and multilingual pupils rarely or never make use of other languages included in their linguistic repertoire. The question now is, which other contextual factors have a beneficial effect on those biand multilinguals so that pupils actually use Italian during classroom instruction.

\subsection{Contextual Factors}

Since only those bi- and multilinguals who have Italian included in their linguistic repertoire actually make use of Italian in the formal educational context, we now briefly refer to results concerning additional contextual factors that support bi- and multilingual pupils to make use of Italian as a second or third language for interaction with their class teacher (cf., Mayr-Keiler, forthcoming) for a deeper and more complex analysis.

Based on the results of the intersection analysis, we identified the following four factors influencing the pupils' use of Italian in the formal context with their class teacher during lessons:

(1) Italian is included in the pupils' linguistic repertoire: as stated earlier (cf. Section 5.2 in this article), if Italian is included in the pupils' linguistic repertoire, they are likely to make use of Italian. However, whether pupils actually make use of it strongly depends on the following additional factors;

(2) School culture which is favourable of cultural and linguistic diversity;

(3) Pupils attend an optional Italian course offered at school: if Italian is offered as an optional course at school, pupils are more likely to make use of Italian after participating in this course; 
(4) If pupils attend an optional Italian course, the duration of participation is relevant.

Summarising the findings, bi- and multilingual subjects actually make use of Italian only if all contextual factors (1)-(4) exist and are thus valid. In fact, those 5 bilinguals and 13 multilinguals who use Italian with their class teacher have Italian in their linguistic repertoire, attend a school aiming at integrating cultural and linguistic diversity into its school programme, attend an optional Italian course at school and participated in that course for five or more years. As for their use of English in the formal educational context, we have seen a discrepancy between the bi- and multilingual pupils. Additional analyses will have to be performed in order to find out more about the interdependencies between the contextual factors that become affective here. Concerning the use of languages other than German, in our case English and Italian, we have seen that bi- and multilinguals rarely make use of them or rather pupils are not provided with opportunities (the right set of contextual factors) which would allow them to make us of other languages.

\section{Discussion and Conclusion}

Statistical and intersection analyses revealed that the actual use of a language other than German within a formal education context depends not only on individual contextual factors but rather on the dynamic interplay and coexistence of such factors. Apart from the fact that interaction with teachers in formal educational contexts are still dominated by German, languages taught as a second or third language at schools, such as English or Italian, seem to be used and consequently accepted for classroom interaction. From an applied linguistics point of view, it would be possible to provide an inclusive formal educational setting e.g., by integrating Romance languages (Rumanian, French, Spanish, Portuguese, etc.) already included in the bi- and multilingual pupils' linguistic repertoires. Since all these languages belong to the same language family and thus share common grammatical structures and lexical items, their linguistic similarities could be used as resources for a more integrative language learning setting in schools. However, as outlined in Section 2 in this article, the linguistic resources of most migrants, and that of minority students are hardly made use of in educational practice (Federal Ministry for Education, Arts and Culture \& Federal Ministry for Science and Research Austria, 2008, p. 28). Consequently, multilingual approaches to language learning such as raising multilingual awareness by using meta- and crosslinguistic interaction methods would be necessary to provide bi- and multilinguals with opportunities to make use of their resources and thus support their learning (Jessner, Allgäuer-Hackl, \& Hofer, 2016).

The possibilities of interpretation we are suggesting here build on already existing research in the field of sociolinguistics focusing on social inclusion and language practices in linguistically and culturally diverse contexts (e.g., Blommaert, Collins, \& Slembrouck, 2005; Otsuji \& Pennycook, 2011; Wei, 2011), studies concentrating on crosslinguistic interactions and language learning in the context of multilingualism (e.g., De Angelis, Jessner, \& Kresic, 2015; Jessner et al., 2016) as well as on educational linguistics dealing with language teaching and learning in multilingual classrooms (e.g., Busch, Jardine, \& Tjoutuku, 2006; Cenoz \& Gorter, 2015; Conteh, 2014; García \& Sylvan, 2011).

Moreover, we have tried to show that language use cannot be regarded as independent of its context since there is complex and dynamic interplay between language practice and the contextual factors creating a specific context. Providing educational frameworks and settings in which linguistic and cultural diversity are not only acknowledged as valuable resources, but where linguistic skills and knowledge of and about languages other than German become integral parts of (language) learning at school, is essential in order to develop a linguistically and socially inclusive school system in Austria.

Finally, the possibilities of interpretation make no claim to completeness and can only briefly hint at the variety of factors and criteria which have to be examined when it comes to trying to understand how bi- and multilingual practices are employed in a formal educational context. What can be seen from these practices, however, is that a deeper and more reflective understanding of the dynamic and complex interactions of contextual and individual factors concerning language choice and use with the aim of social inclusion is needed. Only if schools and teachers come to learn more about these factors may they derive implications for language learning and teaching in inclusive educational settings and thus be able to meet the multilingual challenge (Jessner \& Kramsch, 2015).

\section{Acknowledgments}

We would like to thank the three anonymous reviewers for their suggestions and comments as well as the schools and pupils who participated in our study. Our special thanks go out to the DyME-research group at the University of Innsbruck for their valuable feedback and remarks.

\section{Conflict of Interests}

The authors declare no conflict of interests.

\section{References}

Anderson, B. (1983). Imagined communities. Reflections on the origin and spread of nationalism. London: Verso.

Baker, C. (1992). Attitudes and language. Clevedon: Multilingual Matters.

Blommaert, J., Collins, J., \& Slembrouck, S. (2005). 
Spaces of multilingualism. Language \& Communication, 25(3), 197-216. Retrieved from https://www. researchgate.net/publication/223944571_Spaces_of _Multilingualism

Bruneforth, M., Lassnigg, L., Vogtenhuber, S., Schreiner, C., \& Breit, S. (Eds.). (2016). Nationaler Bildungsbericht Österreich 2015. Das Schulsystem im Spiegel von Daten und Indikatoren (Vol. 1). Graz: Leykam.

Busch, B., Jardine, A., \& Tjoutuku, A. (2006). Language biographies for multilingual learning (Occasional Papers. No. 24). Cape Town: PRAESA.

Cenoz, J., \& Gorter, D. (Eds.). (2015). Multilingual education. Between language learning and translanguaging. Cambridge: Cambridge University Press.

Commission of the European Communities. (2005). Communication from the Commission to the Council and the European Parliament. Draft declaration on guiding principles for sustainable development. Retrieved from http://eur-lex.europa.eu/LexUriServ/ LexUriServ.do?uri=COM:2005:0218:FIN:EN:PDF

Conteh, J. (2014). Second language learning in the early school years: Trends and contexts. ELT Journal, 68(3), 349-351. Retrieved from https://doi.org/ 10.1093/elt/ccu020

Cook, V. J. (2012). Multi-competence. In C. A. Chaplelle (Ed.), The encyclopedia of applied linguistics (pp. 3768-3774). New York: Wiley-Blackwell. Retrieved from http://onlinelibrary.wiley.com/doi/ 10.1002/9781405198431.wbeal0778/full

Cook, V. J., \& Wei, L. (Eds.). (2016). The Cambridge handbook of linguistic multi-competence. Cambridge: Cambridge University Press.

Council of Europe. (2014). Council of Europe language education policy. Council of Europe. Retrieved from http://www.coe.int/t/dg4/linguistic/Division_EN.asp

Davies, B., \& Harré, R. (1990). Positioning: The discursive production of selves. Journal for the Theory of Social Behaviour, 20(1), 43-63.

De Angelis, G., Jessner, U., \& Kresic, M. (Eds.). (2015). Crosslinguistic influence and crosslinguistic interaction in multilingual language learning. London: Bloomsbury Academic.

De Bot, K., Lowie, W., \& Verspoor, M. (2007). A dynamic systems theory approach to second language acquisition. Bilingualism: Language and Cognition, 10(1), 7-21. Retrieved from http://dx.doi.org/ doi:10.1017/S1366728906002732

Dörnyei, Z., MacIntyre, P. D., \& Henry, A. (Eds.). (2014). Motivational dynamics in language learning (1st ed.). Bristol, Buffalo and Toronto: Multilingual Matters.

European Commission. (2000). Charter of fundamental rights in the European Union. Retrieved from http:// www.europarl.europa.eu/charter/pdf/text_en.pdf

Extra, G., \& Yağmur, K. (Eds.). (2004). Urban multilingualism in Europe: Immigrant minority languages at home and school. Clevedon: Multilingual Matters.

Federal Constitutional Law. (2005). B-VG - BGBI. Nr. $1 / 1930$, last amended by BGBI. I Nr. 81/2005, Article
8(1). (1930). Retrieved from https://www.ris.bka.gv. at/GeltendeFassung.wxe?Abfrage=Bundesnormen \& Gesetzesnummer $=10000138$

Federal Ministry for Education. (2012). NMSUmsetzungspaket. Retrieved from https://www.ris. bka.gv.at/Dokumente/BgblAuth/BGBLA_2012_II_185 /COO_2026_100_2_752334.pdf

Federal Ministry for Education. (2017). Erlass: BMB-36. 300/0009-1/2017. Unterrichts-begleitende Sprachstandsbeobachtung, Profilanalysen und Sprachförderung (USB PluS). Retrieved from https://www.bmb. gv.at/schulen/recht/erlaesse/usb_plus_2017.pdf?62 9xwr

Federal Ministry for Education, Arts and Culture, \& Federal Ministry for Science and Research Austria. (Eds.). (2008). Language education policy profile: Country report Austria, 28. Retrieved from http://www.coe. int/t/dg4/linguistic/Source/Austria_CountryReport_ Aug07_EN.doc

Franke, M., \& Mannella, M. (2017). Fact sheets on the European Union. Retrieved from http://www. europarl.europa.eu/ftu/pdf/en/FTU_5.13.6.pdf

Gal, S. (2006). Contradictions of standard language in Europe: Implications for the study of practices and publics. Social Anthropology, 14(2), 163-181.

García, O., \& Sylvan, C. (2011). Pedagogies and practices in multilingual classrooms: Singularities in pluralities. The Modern Language Journal, 95(3), 385-400. Retrieved from http://internationalsnps.org/wpcontent/uploads/Pedagogies-and-Practices.pdf

Gogolin, I. (2008). Der monolinguale Habitus der multilingualen Schule. Münster: Waxmann.

Gomolla, M., \& Radtke, F. O. (2009). Institutionelle Diskriminierung. Die Herstellung ethnischer Differenz in der Schule. Wiesbaden: Vs Verlag für Sozialwissenschaften.

Heller, M. (2012). Rethinking sociolinguistic ethnography: From community and identity to process and practice. In S. Gardner \& M. Martin-Jones (Eds.), Multilingualism, discourse and ethnography (pp. 24-32). New York: Routledge Taylor \& Francis Group.

Herdina, P., \& Jessner, U. (2002). A dynamic model of multilingualism: Perspectives of change in psycholinguistics. Clevedon: Multilingual Matters.

Hufeisen, B., \& Marx, N. (2014). EuroComGerm: Die sieben Siebe: Germanische Sprachen lesen lernen. Herzogenrath: Shaker.

Irvine, J. T., \& Gal, S. (2000). Language ideology and linguistic differentiation. In P. Kroskrity (Ed.), Regimes of language: Ideologies, polities, and identities (pp. 35-84). Santa Fe: School of American Research Press.

Jessner, U., Allgäuer-Hackl, E., \& Hofer, B. (2016). Emerging multilingual awareness in educational context: From theory to practice. The Canadian Modern Language Review, 72(2), 157-182.

Jessner, U., Hofer, B., \& Pinto, M. A. (2015). MKT, Metalinguistischer Kompetenztest: Teil 2. Innsbruck: Studia Universitätsverlag. 
Jessner, U., \& Kramsch, C. (Eds.). (2015). The multilingual challenge: Cross-disciplinary perspectives. Berlin and New York: Mouton de Gruyter.

Kecskes, I. (2008). Duelling contexts: A dynamic model of meaning. Journal of Pragmatics, 40, 385-406.

Kramsch, C. (1993). Context and culture in language teaching. Oxford: Oxford University Press.

Kramsch, C. (2015). The multilingual subject: What foreign language learners say about their experience and why it matters. Oxford: Oxford University Press.

Kristeva, J. (1980). Desire in language: A semiotic approach to literature and art. New York: Columbia University Press.

Krumm, H.-J. (2003). Integration durch Sprache-Ein falsches Versprechen? Oder: Bedingungen für einen integrationsfördernden Sprachunterricht. Info DaFInformationen Deutsch als Fremdsprache, 30(5), 413-427.

Larsen-Freeman, D., \& Cameron, L. (2008). Complex systems and applied linguistics. Oxford: Oxford University Press.

Lengyel, D. (2012). Sprachstandsfeststellung bei mehrsprachigen Kindern im Elementarbereich: Eine Expertise der Weiterbildungsinitiative Frühpädagogische Fachkräfte (WiFF); [Sprache]. München: DJI.

Mayr-Keiler, K. (forthcoming). The dynamics of language use and contexts. A study on mono-, bi-, and multilingual school children in Tyrol (Doctoral dissertation).

Otsuji, E., \& Pennycook, A. (2011). Social inclusion and metrolingual practices. International Journal of Bilingual Education and Bilingualism, 14(4), 413426. Retrieved from http://www.tandfonline.com/ doi/abs/10.1080/13670050.2011.573065
Pennycook, A. (1994). Incommensurable discourses? Applied Linguistics, 15(2), 115-138. Retrieved from doi:10.1093/applin/15.2.115

R Development Core Team. (2005). R: A language and environment for statistical computing, reference index version 2.2.1. Vienna, Austria: R Foundation for Statistical Computing.

Shohamy, E. G. (2001). The power of tests: The impact of language tests on teaching and learning. London: Longman.

Silverstein, M. (1979). Language structure and linguistic ideology. In R. Clyne, W. Hanks, \& C. Hofbauer (Eds.), The elements: A parasession on linguistic units and levels (pp. 193-247). Chicago: Chicago Linguistic Society.

Statistik Austria. (2016). Migration \& integration. Numbers, data, indicators. Retrieved from http://www. integrationsfonds.at/fileadmin/content/migrationint egration-2016.pdf

Van Dijk, T. A. (2010). Discourse and context: A sociocognitive approach. Cambridge: Cambridge University Press.

Weber, J.-J., \& Horner, K. (2012). Introducing multilingualism-A social approach (1st ed.). London and New York: Routledge.

Wei, L. (2011). Multilinguality, multimodality, and multicompetence: Code- and modeswitching by minority ethnic children in complementary schools. The Modern Language Journal, 95(3), 370-384. Retrieved from http://onlinelibrary.wiley.com/doi/10.1111/ j.1540-4781.2011.01209.x/abstract

Woolard, K., \& Schieffelin, B. (1994). Language ideology. Annual Review of Anthropology, 23, 55-82.

\section{About the Authors}
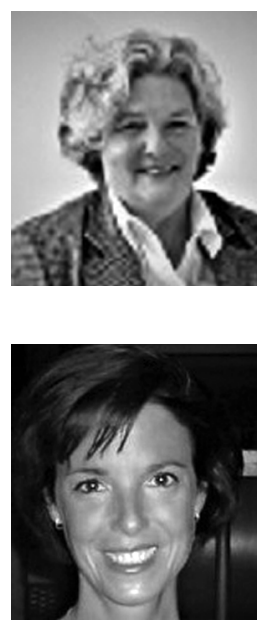

Ulrike Jessner is a Professor at the University of Innsbruck (Austria) and the University of Pannonia, Veszprem (Hungary). She is widely published in the field of third language acquisition and multilingualism with a special focus on the acquisition of English in multilingual contexts. She is a founding member and President of the International Association of Multilingualism. She chairs the Regional Educational Competence Centre "German \& Multilingualism" and is a founding editor of the International Journal of Multilingualism and the book series Trends in Applied Linguistics (with Claire Kramsch at UC Berkeley).

Kerstin Mayr-Keiler is a PhD student in applied linguistics and media science at the University of Innsbruck (Austria). Her research interests stand at the intersection of multilingualism, sociolinguistics, and social inclusion. Her dissertation will explore the dynamics of language use of mono-, bi-, and multilingual pupils in different contexts in the urban area of Innsbruck/Austria. She is a lecturer, researcher, and head of the Centre for Research and Knowledge Management at the Pedagogical University Tyrol. 